\title{
SATELLITE BASED DROUGHT ASSESSMENT OVER LATUR, INDIA USING SOIL MOISTURE DERIVED FROM SMOS
}

\author{
Dhanashri Kolekar ${ }^{1, *}$, V. S. K. Vanama ${ }^{2}$, Y. S. Rao ${ }^{1}$ \\ ${ }^{1}$ Centre of Studies in Resources Engineering, Indian Institute of Technology Bombay, India - dskolekar24@gmail.com \\ ${ }^{2}$ Centre for Urban Science and Engineering, Indian Institute of Technology Bombay, India
}

\section{Commission V, SS: Disaster Monitoring, Damage Assessment and Risk Reduction}

KEY WORDS: Soil Moisture, SMOS, Drought, Standardized Precipitation Index (SPI), Standardized Precipitation Evapotranspiration Index (SPEI)

\begin{abstract}
:
Climatological variables such as rainfall, temperature have been extensively used by researchers for drought monitoring at a larger spatial region. These variables have a direct influence on the soil moisture which in turn extends the application of soil moisture in drought assessment. With the advancement of technology, various satellites provide soil moisture data at different spatio-temporal resolutions. In this article, soil moisture obtained from Soil Moisture Ocean Salinity (SMOS) is used to analyze the drought condition over Latur district in Maharashtra, India. The monthly soil moisture derived by averaging the daily data for the years 2010 to 2015 is compared with two drought indices, i.e. Standardized Precipitation Index (SPI) calculated for years 2010 to 2015 and Standardized Precipitation-Evapotranspiration Index (SPEI) calculated for years 2010 to 2013. Even though the overall correlation among the indices with the soil moisture is not significant, the seasonal (summer) correlation is significant. From the results, it is identified that SMOS derived soil moisture can be used as a potential parameter in drought assessment.
\end{abstract}

\section{INTRODUCTION}

Drought is a major disaster affecting the society with increasing severity, duration and spatial extent (Mallya et al., 2016). Broadly, drought is classified into three classes namely meteorological, agricultural and hydrological droughts. If the mean annual rainfall in a region is less than $75 \%$ of its normal rainfall, it is known as meteorological drought (Kendale, 2011). Knowledge of type, severity, and spatial location of drought helps the government agencies to take effective measures and policy formulation.

Standardized Precipitation Index (SPI) (McKee et al., 1993) and Standardized Precipitation-Evapotranspiration Index (SPEI) are the well-established indices for drought monitoring over larger spatial regions. SPEI is an extension of SPI that also captures the effect of potential evapotranspiration (PET) on drought (Vicente-Serrano et al., 2010). These indices can be calculated for various time scales. The indices computed with one or two months time scale is used for meteorological drought assessment. Based on the range of these indices value the drought intensity of a region is assessed as shown in Table 1

\begin{tabular}{|l|c|}
\hline SPI Value & Condition \\
\hline $2.0+$ & Extremely Wet \\
1.55 to 1.99 & Very Wet \\
1.0 to 1.49 & Moderately Wet \\
-0.99 to +0.99 & Near Normal \\
-1.0 to -1.49 & Moderately Dry \\
-1.55 to -1.99 & Severely Dry \\
-2.0 and less & Extremely Dry \\
\hline
\end{tabular}

Table 1. SPI values and corresponding condition (McKee et al., 1993).
The variables used for computing these indices have a direct influence on the soil moisture which in turn extends the application of soil moisture in drought assessment. Many studies have shown the application of soil moisture derived from in-situ measurements, and remote sensing techniques in drought assessment. Due to the limitations (spatial coverage, temporal resolution and high resource consumption) in the insitu measurements, soil moisture derived from remote sensing techniques are often used by the researchers. Soil moisture can be obtained from both the optical and microwave remote sensing techniques. However, the optical data has limitations such as cloud cover, less spatial coverage and low temporal resolution. Therefore, passive microwave remote sensing is more preferred due to its all weather capacity, day-night coverage, high temporal resolution and sensitivity to dielectric constant of soil.

A study done by (Thiruvengadam and Rao, 2016) shows a positive spatio-temporal correlation of AMSR-E soil moisture with precipitation. Many studies were carried out to find an association of soil moisture with drought condition using various drought indices. Palmer Drought Severity Index (PDSI), a widely used drought index, shows a significant correlation with surface soil moisture (Dai et al., 2004). A similar study done by (Scaini et al., 2015) found that relations between soil moisture and drought in-dices such as SPI and SPEI are promising; but higher correlation is seen with in-situ measurements than SMOS soil moisture. Soil moisture is an effective tool for monitoring agricultural drought as well. CMI (Crop Moisture Index) and the AWD (Atmospheric Water Deficit index) are interrelated with soil moisture regarding time series variation, as well as in correlation (Mart'inez-Fernandez'

\footnotetext{
* Corresponding author
} 
et al., 2015). Soil Water Deficit Index (SWDI) computed based on satellite soil moisture data can pose an effective tool for agricultural drought monitoring. (Mart'inez-Fernandez' et al., 2017). Soil Moisture Agricultural Drought Index (SMADI), has been used by (Sanchez' et al., 2017) for drought monitor-ing which shows a good correlation with different agricultural drought indices. Effect of drought on crop yield is studied with the variation of soil moisture (Chakrabarti et al., 2014).

Soil moisture obtained from various passive microwave satellite sensors such as Soil Moisture and Ocean Salinity (SMOS)

(Mart'1nez-Fernandez' et al., 2017), Advanced Microwave Scan-ning Radiometer-EOS (AMSR-E) (Thiruvengadam and Rao, 2016) or Advanced Scatterometer (ASCAT) (Zhang et al., 2015) describes its ability for drought assessment.

The main aim of the study is to identify the potential of SMOS derived soil moisture in drought assessment for Latur district in Maharashtra state, India. The next section describes the selected study area and the data sets used. Section III describes the methodology and the results are shown in section IV and conclusion in section V.

\section{STUDY AREA AND DATASET}

Latur district in Maharashtra state, India spans between 1752 'N to $1850^{\prime} \mathrm{N}$ and $7618^{\prime} \mathrm{E}$ to $7912^{\prime} \mathrm{E}$ with total area of $7157 \mathrm{sq}$ $\mathrm{km}$ as shown in Figure 1. The district lies on Deccan Plateau

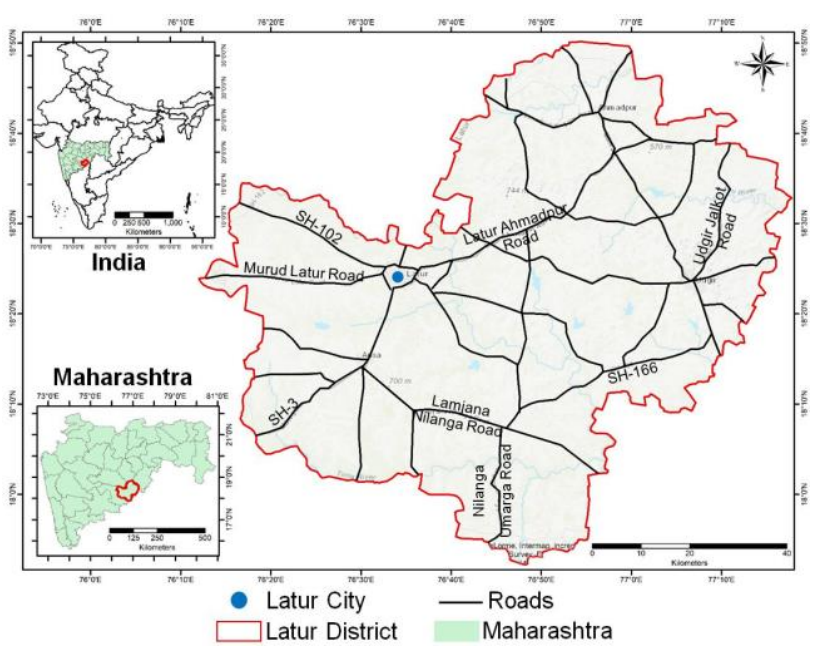

Figure 1. Study area showing Latur district in Maharashtra state of India.

at an average elevation of $631 \mathrm{~m}$ above mean sea level. Latur district has average 600 to $800 \mathrm{~mm}$ rainfall in monsoon season (July-September) which is quite uncertain. In the year 2015, Latur received $372 \mathrm{~mm}$ rainfall in monsoon season which was $51 \%$ less than normal rainfall. The monthly rainfall was $81 \mathrm{~mm}$, $31.5 \mathrm{~mm}, 105.4 \mathrm{~mm}$, and $154.1 \mathrm{~mm}$ in June, July, and in September which had $-44 \%,-88 \%,-52 \%$ and $-9 \%$ departure from normal rainfall respectively (Kaur, 2016). The received rainfall was very unevenly distributed. As a result of less rainfall, Latur district suffered with huge water scarcity and as a consequence, water storage depleted to extreme level, making it difficult to maintain till 2016 monsoon. Latur was then fed with water from Miraj taluka in Sangli District by train with ten wagons carrying 50,000 litres of drinking water each. Therefore, meteorological drought of Latur is the focus of the study.

The daily rainfall (PRCP) and temperature data are obtained from Indian Meteorological Department (IMD) at a spatial resolution of $0.25 \times 0.25$ and $1 \times 1$ respectively. The rainfall data is avail-able from 1951 to 2015 whereas the temperature is available from 1951 to 2013. The SMOS Level-3 daily soil moisture data (ascending, descending passes) is obtained from BEC (Barcelona Expert Centre). As the availability of SMOS data is from 01 Jan 2010, the entire analysis is limited to 01 Jan 2010 to 31 Dec 2015 in case of SPI and up to 31 Dec 2013 in case of SPEI.

\section{METHODOLOGY}

The methodology adopted for the study is shown in the Figure 2 . The daily temperature provided by IMD is available in

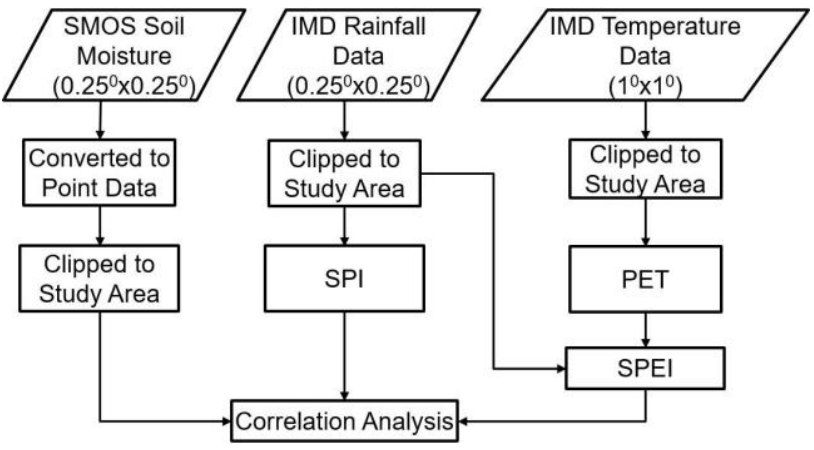

Figure 2. Methodology for drought assessment using SMOS and IMD rainfall and temperature data

three aggregation levels, i.e. mean, maximum (TMAX) and minimum (TMIN) out of which only mean temperature data is not used. Pre-processing of the data includes removal of outliers followed by filling with averaged values of two previous and post months. The daily rainfall and temperature data is clipped to the study area extent and then monthly averaged data are extracted for all the years. SPI is computed on monthly basis for two time scales (one and three months) in RStudio by SPI library (Neves, 2011) where monthly temporal averaged rainfall is the input variable. Two intermediate variables i.e. Potential evapotranspiration (PET) and climate water balance which are required in SPEI computation are generated. The PET is computed by Hargreaves-Samani equation with TMAX and TMIN as the input variables. The climate water balance is computed by taking the difference of precipitation and PET ("PRCP-PET"). SPEI is computed on monthly basis for two time scales (one and three months) in RStu-dio by SPEI library (Santiago Beguera, 2017) where climate water balance is the input variable.

The SMOS soil moisture that is obtained in netCDF format is converted to geotiff format in ArcGIS 10.1 for ease of analysis. Similar to the indices, the soil moisture is also clipped to the study area. One raster data is converted into point data and all the temporal raster data is extracted to this point file by using "Extract Multi Values to Points" in ArcGIS. The daily ascending and descending pass soil moisture is averaged 
spatially and temporally to monthly data for the years 2010 to 2015.

\section{RESULTS AND DISCUSSIONS}

The time series plot of all the variables (BAL, PET, TMIN, TMAX, PRCP) is shown in the Figure 3. As the influence of rainfall on soil moisture does not hold for a long duration, indices derived with one and three-month time scale are considered for analysis. The monthly temporal variation of SPI for the years 2010 to 2015 is shown in the Figure 4. The time series plots of SPI and SPEI are shown in Figures 5 and 6 respectively.

It can be seen from the Figures 5 and 6 that Latur has experienced severe drought during 1972 and 2009. In the duration of SMOS soil moisture availability, Latur experienced drought conditions during 2011 and 2015.

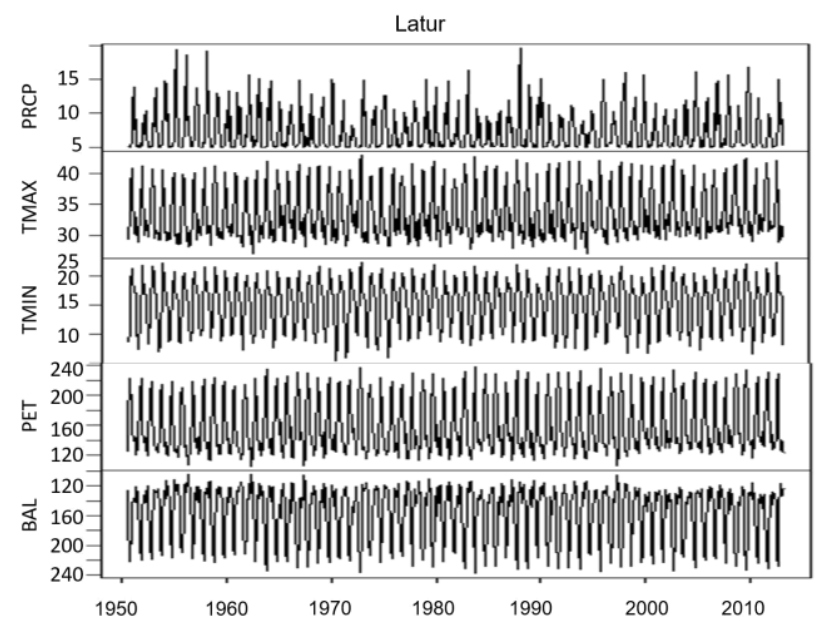

Figure 3. Distribution of Precipitation, TMAX, TMIN, PET, and Climate water balance data over Latur district.

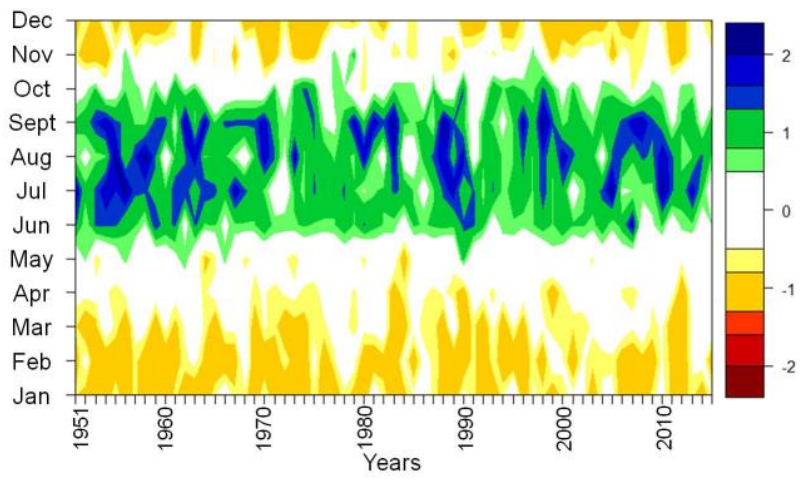

Figure 4. Monthly temporal variation of SPI for the years 2010 to 2015 over Latur district.

In order to do the quantitative assessment of the SMOS soil moisture for drought monitoring, a correlation analysis with the indices is carried out. The indices derived with one month time scale are used in correlation analysis as three-month time scale is not significant. The range of values for the variables such as

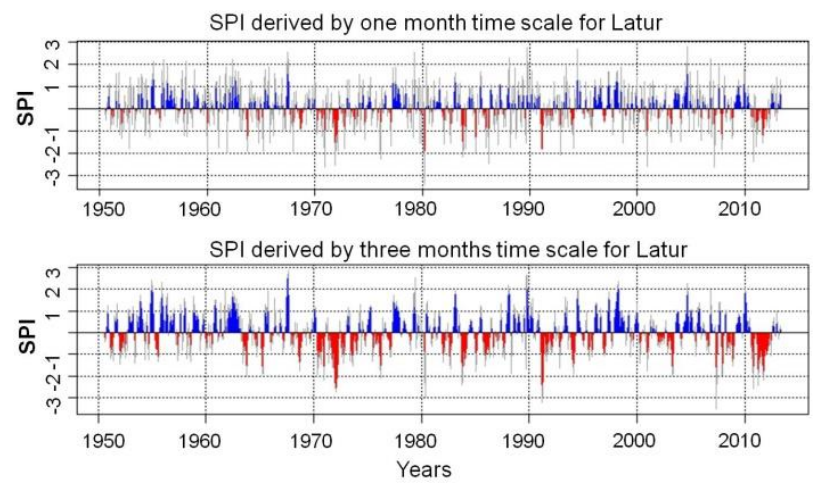

Figure 5. SPI calculated for one and three month time scales for Latur district.
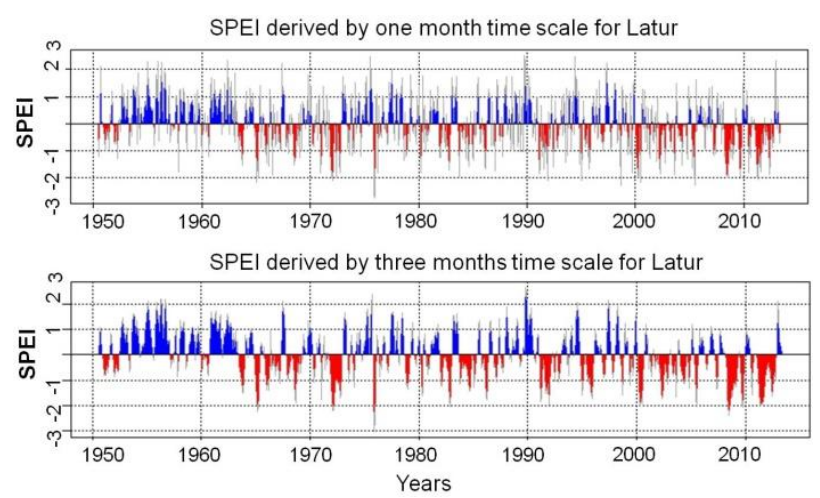

Figure 6. SPEI calculated for one and three month time scales for Latur district.

scale are used in correlation analysis as three-month time scale is not significant. The range of values for the variables such as soil moisture, SPI and SPEI are not same. So, these variables are normalized by simple min-max stretch for a possible comparative assessment. To observe the correlation of variables easily the stacked time series plots are created. The Figure 7 shows the monthly temporal variation of soil moisture against SPI for the years 2010 to 2015 . The Figure 8 shows the monthly temporal variation of soil moisture against SPEI for the years 2010 to 2013.

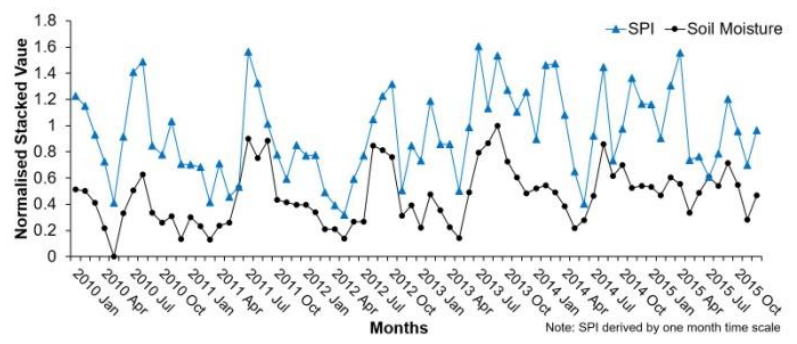

Figure 7. Monthly temporal variation of soil moisture against SPI.

The overall correlation of soil moisture with SPI and SPEI indices has a weak association. In case of SPEI, a moderate correlation with a Pearson correlation coefficient (r) of 0:379 is seen which is due to the inclusion of temperature variable. So, a 


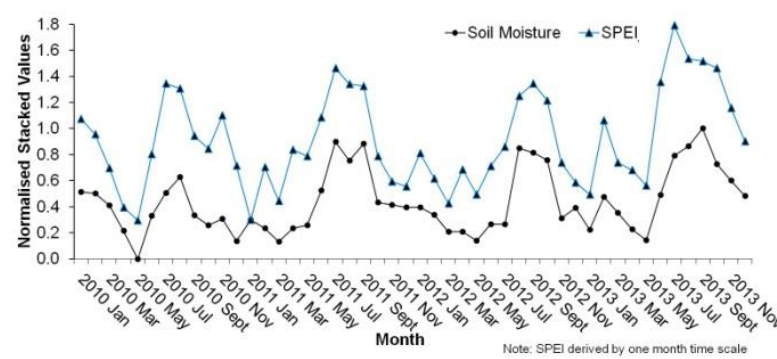

Figure 8. Monthly temporal variation of soil moisture against SPEI.

season wise de-tailed analysis was performed to understand the drought situation over Latur. Two seasons summer (FebruaryMay) and monsoon (June-September) are considered.

In summer season, SPI has a significant correlation $(\mathrm{r}=0: 751)$ whereas SPEI has a mild correlation $(\mathrm{r}=0: 287)$ with SMOS soil moisture. This might be a limitation of temperature data which is available at very coarse resolution than the other datasets. The Figures 9 and 10 show the monthly temporal variation of soil moisture against SPI and SPEI for summer seasons respectively.

It is inferred from Figure 4 that the land surface condition during monsoon season varies from moderately wet to extremely wet. Also, soil moisture is largely affected by drainage condition. As a result a low correlation is observed between the indices and the soil moisture. SPI has a low correlation $(\mathrm{r}=0: 1)$, whereas SPEI has a very low correlation $(r=0: 04)$ with SMOS soil moisture. The Figures 11 and 12 show the monthly temporal variation of soil moisture against SPI and SPEI for monsoon seasons respectively.

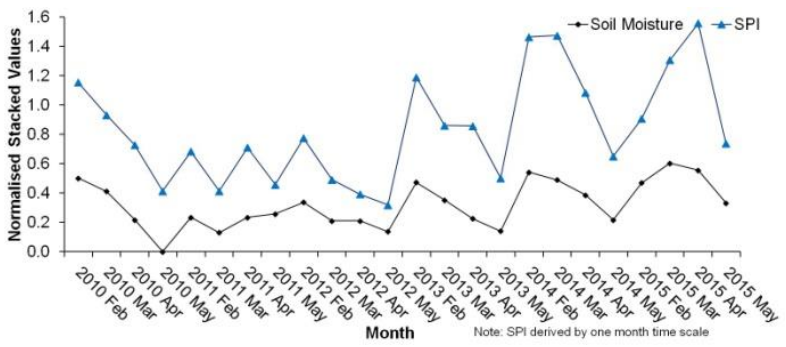

Figure 9. Monthly temporal variation of soil moisture against SPI during summer.

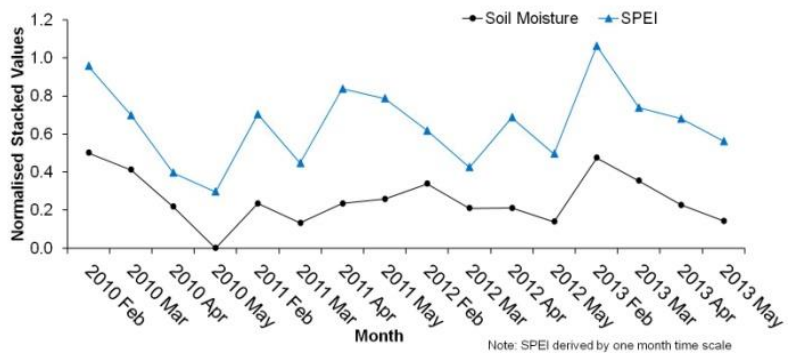

Figure 10. Monthly temporal variation of soil moisture against SPEI during Summer.

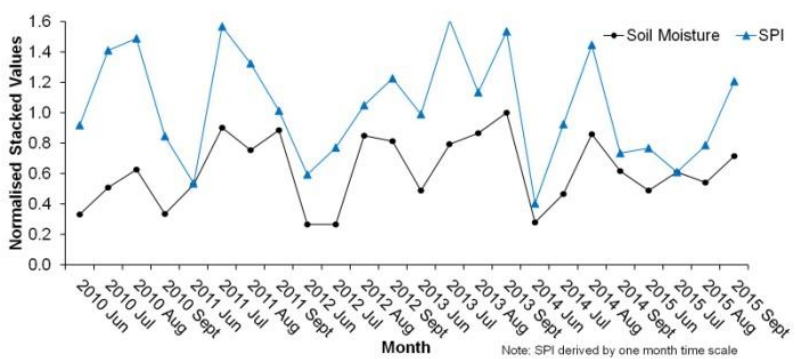

Figure 11. Monthly temporal variation of soil moisture against SPI during Monsoon.

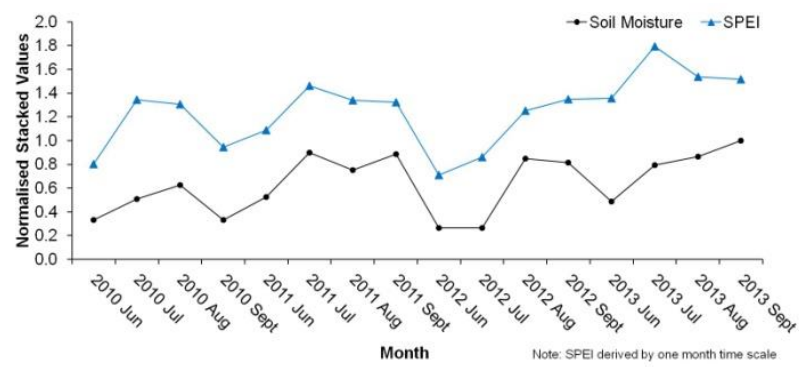

Figure 12. Monthly temporal variation of soil moisture against SPEI during Monsoon.

\section{CONCLUSION}

The results of the study revealed that SMOS derived soil moisture can be used as a potential parameter in drought assessment. The study also found that the better performance of SPEI with soil moisture is attributed to temperature variable. A more detailed study, considering the utility of other variables like wind velocity and surface humidity is required to identify the robustness of soil moisture in drought assessment. The study can be extended to agricultural and hydrological drought, as they involve several climatological variables which influence soil moisture.

\section{ACKNOWLEDGEMENTS}

The authors would like to thank Prof. Raaj Ramsankaran, Department of Civil Engineering, IIT Bombay for providing the IMD data. The authors also thank to Barcelona Expert Centre for providing the open source SMOS soil moisture data.

\section{REFERENCES}

Chakrabarti, S., Bongiovanni, T., Judge, J., Zotarelli, L. and Bayer, C., 2014. Assimilation of smos soil moisture for quantify-ing drought impacts on crop yield in agricultural regions. IEEE Journal of Selected Topics in Applied Earth Observations and Remote Sensing 7(9), pp. 3867-3879.

Dai, A., Trenberth, K. E. and Qian, T., 2004. A global dataset of palmer drought severity index for 1870-2002: Relationship with soil moisture and effects of surface warming. Journal of Hydrometeorology 5(6), pp. 1117-1130.

Kaur, Surinder, M. K. P., 2016. Rainfall statistics of in-dia 2015. In: Indian Meteorological Department (Ministry of Earth 
Sciences) REPORT NO. :ESSO/IMD/HS R. F. REPO RT/04(2016)/22, IMD.

Kendale, B. M., 2011. 1970-73 drought of maharashtra: with special reference to state and legislative response.

Mallya, G., Mishra, V., Niyogi, D., Tripathi, S. and Govindaraju, R. S., 2016. Trends and variability of droughts over the indian monsoon region. Weather and Climate Extremes 12, pp. 43-68.

Mart'inez-Fernandez,' J., Gonzalez'-Zamora, A., Sanchez,' N. and Pablos, M., 2017. Cci soil moisture for long-term agricultural drought monitoring: A case study in spain. In: 2017 IEEE Inter-national Geoscience and Remote Sensing Symposium (IGARSS), IEEE, pp. 1985-1988.

Mart'inez-Fernandez,' J., Sanchez,' N., Gonzalez'-Zamora, A., Gumuzzio-Such, A. and Herrero-Jimenez,' C. M., 2015. Feasibil-ity of the smos soil moisture for agricultural drought monitoring: Assessment with the soil water deficit index. In: Geoscience and Remote Sensing Symposium (IGARSS), 2015 IEEE International, IEEE, pp. 976-979.

McKee, T. B., Doesken, N. J., Kleist, J. et al., 1993. The relationship of drought frequency and duration to time scales. In: Proceedings of the 8th Conference on Applied Climatology, Vol. 17number 22, American Meteorological Society Boston, MA, pp. 179-183.

Sanchez,' N., Gonzalez'-Zamora, A., Mart'inez-Fernandez,' J., Piles, M., Pablos, M., Wardlow, B., Tadesse, T. and Svoboda, M., 2017. Preliminary assessment of an integrated smos and modis application for global agricultural drought monitoring. In: Geo-science and Remote Sensing Symposium (IGARSS), 2017 IEEE International, IEEE, pp. 2000-2003.

Santiago Beguera, S. M. V.-S., 2017. SPEI: Calculation of the Standardised Precipitation-Evapotranspiration Index. R package version 1.7 .

Scaini, A., Sanchez,' N., Vicente-Serrano, S. M. and Mart'inezFernandez,' J., 2015. Smos-derived soil moisture anomalies and drought indices: a comparative analysis using in situ measurements. Hydrological processes 29(3), pp. 373-383.

Thiruvengadam, P. and Rao, Y., 2016. Spatio-temporal variation of soil moisture and drought monitoring using passive microwave remote sensing. In: Geoscience and Remote Sensing Symposium (IGARSS), 2016 IEEE International, IEEE, pp. 3126-3129.

Vicente-Serrano, S. M., Beguer'1a, S. and Lopez'-Moreno, J. I., 2010. A multiscalar drought index sensitive to global warming: the standardized precipitation evapotranspiration index. Journal of climate 23(7), pp. 1696-1718.

Zhang, J., Becker-Reshef, I. and Justice, C., 2015. Evaluation of the ascat surface soil moisture product for agricultural drought monitoring in usa. In: Geoscience and Remote Sensing Symposium (IGARSS), 2015 IEEE International, IEEE, pp. 669-672. 